\title{
ONE SETTLER STUDENT'S STORY ON INCORPORATING INDIGENOUS KNOWLEDGES IN ENGINEERING CURRICULA
}

\author{
Victoria Thomsen ${ }^{a *}$, Jill Seniuk Cicek ${ }^{b}$, Afua Mante ${ }^{c}$, Shawn Bailey ${ }^{d}$, and Farhoud Delijani ${ }^{b}$ \\ ${ }^{a}$ Department of Biosystems Engineering, ${ }^{\mathrm{b}}$ Centre for Engineering Professional Practice \& Engineering Education, \\ ${ }^{\mathrm{c}}$ Faculty of Agricultural and Food Sciences, ${ }^{\mathrm{d}}$ Faculty of Architecture, University of Manitoba \\ thomsenv@myumanitoba.ca*
}

\begin{abstract}
The University of Manitoba Price Faculty of Engineering is actively working on initiatives to increase Indigenous representation and ideology in engineering education. The initiatives aim to create ethical and equitable space for Indigenous Peoples, so their knowledges and perspectives are visible and valued in the Price Faculty of Engineering community. An Elder-inResident presented to an engineering ethics class the realities Indigenous communities face and how to work with Indigenous Peoples at the intersection of engineering projects such as oil and gas, hydroelectricity, and community infrastructure. This study uses the threedimensional space narrative methodology and boundarycrossing theory to realize the impact on students' learning. The student's perspective negotiated and represented in this study acts as an artifact of boundary crossing and provides insight into the exchange of cross-cultural knowledge. Findings reveal a distinction between relationship and knowledge, where knowledge exchange is dependent on the relationship between people. Key factors contributing to a relationship include identifying each other's historical backgrounds; situational contexts, and values, which require active listening; genuine curiosity; empathy; and time. The research presented in this paper is part of a more extensive case study exploring the impact on students' learning when integrating Indigenous knowledges and perspectives into engineering education and is approved by the University of Manitoba's Research Ethics Board.
\end{abstract}

Keywords: Engineering education, Indigenous knowledges, boundary-crossing, student learning, TRC Calls to Action

\section{INTRODUCTION}

Descendants of the First Peoples, from Treaty One Territory and the Homeland of the Métis Nation on which the oldest European University in Western Canada sits, have had the courage and strength to share, inside academic walls, their messages on the cross-cultural and ideological conflict in our society today. They are creating influence within the same systems and societies that have excluded them. Indigenous Peoples, because of colonization, were segregated from settler Canadians by the Pass System,
Indian Reservations, Indian Residential Schools and enfranchisement [1]. However, Indigenous Peoples and their voices have persevered through the gruelling hardships of cultural genocide, and the Canadian government's historical planned and intentional assimilation efforts are slowly becoming common knowledge to citizens as the unjust treatment of First Nation, Métis and Inuit human beings and their lands [2].

Colonialism, defined by Maldonado-Torres, "denotes a political and economic relation in which the sovereignty of a nation or people rests on the power of another nation, which makes such nation an empire" [3]. To counter colonialism, decolonization "involves intentional and concerted action to challenge divisive and destructive colonial entities that harm and separate people" [4]. According to Ottmann (2017), decolonization unite people's efforts to form respectful relationships and hear each other's stories [4]. People are becoming more aware of themselves and how they relate to others and the environment, which is evident in engineering education initiatives such as Diversity \& Inclusion, Sustainability, Leadership, and Indigenizing the curriculum. However, sociological factors such as racism, conserved by farreaching messages of self-interest are challenges we have to overcome to acknowledge other people respectfully.

How do we as educators and students go about developing mutually respectful relationships with Indigenous Peoples in engineering education? The Blackfoot Elder and scholar, Dr. Crowshoe (2019) developed the concept of 'ethical space' to provide a framework for reconciliation [5]. Unlike colonialism, ethical space "is a model for equitable interaction that respects the fundamental integrity of both knowledge systems, and prevents one knowledge system from interfering with or overtaking the other" [5]. In their final report, the Truth and Reconciliation Commission of Canada "defines reconciliation as an ongoing process of establishing and maintaining respectful relationships" [2]. They highlight that reconciliation is a process, not an outcome, that requires the repair of damaged trust through actions that support societal change [2].

This implies that on the whole, all people in Canada, both Indigenous and settler/newcomers, belong and have a place of belonging. Therefore, the authors ask, how does post-secondary education, and engineering education 
belong in Indigenous Territory and with Indigenous ways of knowing. Pidgeon (2016) cautions using a checklist approach to Indigenizing higher education without ensuring the initiatives are positively impacting Indigenous students, staff and faculty's lived experiences [6]. Kovach et al. (2015) offer another caution regarding the impact of Indigenization on non-Indigenous students, and the emotional work that could look like shame, fear, grief, and denial, associated with unpacking colonialism and racism in a deeply reflective way [7]. Andreotti et al. (2015) highlight a common tendency of settlers to 'fix' the mainstream system to be inclusive of marginalized subjects, which only perpetuates the colonial system instead of adapting alternatives that pivot the system [8]. To have Indigenous Peoples, ways of knowing, and perspectives represented in the engineering curricula in ethical space, is to critique epistemological dominance and the hegemonic ontological foundation of our academic institutions and our society [8].

Very little research is published on initiatives to foster a sense of belonging of Indigenous Peoples, ways of knowing, and perspectives in the engineering education system in Canada, let alone assessing such initiatives' impacts. More literature is present in other disciplines such as Education and Social Work [7][9][10]. A Participatory Action Research (PAR) project was conducted in 2019 to understand better what Indigenous initiatives were underway in Canadian accredited engineering programs. This research united Indigenous and non-Indigenous engineering faculty and staff across Canada, sharing their work and collaborating in efforts to "create an ethical space in engineering education for Indigenous and western knowledges, perspectives, principles and values to coexist"'[11]. A team of Indigenous and non-Indigenous engineering educators worked with contributors across Canada to identify 11 different areas of Indigenous initiatives in Canadian engineering education programs, which included; outreach, access programs, research partnerships, guiding committees, engineering faculty/job positions, engineering curricula, presence of Elders/knowledge holders, student organizations, and cultural training workshops [11]. Simultaneously, the Manager of Diversity, Equity and Inclusion at Engineers Canada began hosting the Decolonizing and Indigenizing Engineering Education Network (DIEEN), a community that grew out of, and merged two previous groups that had already been meeting to discuss Indigenous engineering curricula and engineering access programs and outreach. The DIEEN supports Indigenous and non-Indigenous faculty and staff involved in Indigenous initiatives by providing a consistent and organized collaborative platform [12]. These Indigenous initiatives and the DIEEN working group are examples of creating ethical space in engineering education. The work of Seniuk Cicek et al. (2019), with contributions from 22 accredited engineering programs and four engineering organizations, with
Indigenous and non-Indigenous contributors show the importance of collaboration and coordination to create ethical space in engineering education [11].

At the University of Manitoba, in the Price Faculty of Engineering, work is being done to create ethical and equitable space in engineering education. In one initiative, an Indigenous Elder-in-Residence is sharing his knowledges, perspectives, and spirit with engineering students as a guest instructor in an engineering classroom. The research presented in this paper tells the story of one engineering student's learning when presented with Indigenous Knowledges and perspectives by the Elder-inResidence.

\subsection{Authors Positionality}

Victoria is 3rd generation Canadian of European descent and raised in Treaty 6 Territory, and Homeland of Métis Nation Region 4. She is passionate about learning from Indigenous Peoples and finding ways to be an ally in engineering education. Jillian is a white settler woman who grew up on Treaty One Territory and in the Homeland of the Métis Nation. She is a mother, wife, daughter, sister, and aunt. She is involved in this work because she knows it is our legal, moral, and ethical responsibility to decolonize Canadian educational institutions and systems, and make equitable space for Indigenous Peoples and their ways of being and knowing. Afua is an African woman, a Post-Doctoral Fellow and Engineer-in-training living on Treaty One Territory. She is traditionally connected with the Kwahu Peoples of Ghana. She is in this space because she has learned that a deeper relationship occurs when we learn about others' journey, view the world through their lenses and find a common place to thrive together. Shawn is a Métis architect who spent his childhood living on Lake of the Woods, Ontario. Growing up in a rich natural context provided him with sensitivity and respect towards nature, and he is inspired to build relationships with the land, create a lower impact model, and tackle environmental and cultural matters head-on. Farhoud is originally from Iran and has been living in Canada for the past twenty years. He is a professional engineer and an instructor with the Price Faculty of Engineering at the University of Manitoba. Farhoud is interested in green and sustainable building materials and buildings. Farhoud teaches a course called Technology, Society and the Future at the University of Manitoba and believes our future ready-to-practice young engineers need to know more about Indigenous Peoples ways of knowing, interacting, doing, and building.

\subsection{Ethics}

This study was approved by the Education/Nursing Research Ethics board at the University of Manitoba. The participant whose story told here consented to participate 
in this study, and to have their story told in this conference paper using their pseudonym of choice.

\section{THEORETICAL FRAMEWORK}

Boundary crossing theory makes visible the discontinuities and continuities between communities of practice, in this case Western engineering education and Indigenous pedagogies. Boundary crossing is grounded in dialogicality and, like the framework of ethical space, "involves the dialogue between multiple perspectives and parties without implying or seeking homogeneity" [13]. The theory provides a lens to view engineering students engagement at a socio-cultural intersection, referred to as a 3rd space [13]. The dialogical learning mechanisms that are considered to take place at the boundary are: identification, coordination, reflection and transformation [13]. This 3rd space may be comparable to Dr. Crowshoe's ethical space if the negotiation and sense-making of different identities can harmoniously co-exist [5][13]. Boundary crossing theory can be the lens through which to view transdisciplinary research on engineering-related projects, which require the interaction between people in cross-disciplines and cross-cultures [14][15][16].

\section{METHODOLOGY}

Qualitative research with the narrative threedimensional space approach broadly considers the participants' detailed personal experience and interaction with others [17]. This type of research aims to empower individuals to share their stories in a way that is not overpowered by the researcher's voice [18]. A 90-minute conversation was held with a recently graduated mechanical engineering student regarding the impact on his learning when an Elder-in-Residence spoke in his Technology, Society, and the Future course, a core course in the engineering curriculum in the Price Faculty of Engineering. The findings are the student's story, restoried from the discussion transcript using the threedimensional space narrative methodology. The story was negotiated with the student for meaning. This form of qualitative research conveys people's stories without restrictions imposed on by formal academic writing structures [18]. Learning through story is also in alignment with practices of Indigenous pedagogies [19]. The student's story shared with us as a gift acts as an artifact of boundarycrossing to provide insight on the exchange of crosscultural knowledge.

\section{FINDINGS}

\subsection{Jean-Baptiste's Story}

After graduating from the mechanical engineering program at the University of Manitoba, working as a missionary overseas, and spending time at home during the Covid pandemic, Jean-Baptiste (a pseudonym) sat with us (the principal researcher and graduate student) in virtual space (WebEx) and carefully reflected on his broad educational journey. As a man of European descent born and raised in Canada, Jean-Baptiste shared how a guest lecture from an Indigenous Elder in an engineering course impacted him.

Jean-Baptiste described that the purpose of engineering education was to teach future engineers how to look at problems, so they can assess them from various angles or perspectives, which include the perspectives of the people, groups, and stakeholders who are being affected in the project so that the design or solution developed meets the needs of people from a larger point of view, rather than from the designer's default point of view.

Jean-Baptiste felt that one way of introducing a broader perspective to engineering students is to have an Indigenous guest lecture present on their life experiences and work. About 50 students were attending the Technology, Society and the Future engineering course with Jean-Baptiste, the day Elder Meade, from the Métis settlement of Manigotagan, presented to the class on how to work with Indigenous Peoples at the intersection of engineering projects in good ways.

That day Jean-Baptiste heard a perspective that was entirely new for him. A perspective from an Indigenous person with years of experience navigating both Indigenous and Western worldviews and situations. Until this point, Jean-Baptiste had not heard Indigenous perspectives on how Indigenous Peoples wanted to be engaged in engineering projects. Elder Meade helped JeanBaptiste see what this engagement could look like, and how it differed from what the engineering profession defined.

Jean-Baptiste learned the importance of relationship from an Indigenous perspective and how the process was different than what engineers commonly engage in which is dialogue for the sake of a project. The relational element shared with Jean-Baptiste and the class included visiting and sitting down with the community Elders and leaders, listening to them and learning about who they are, their values, and their history. More details and nuances were involved in understanding their context rather than an organized meeting to only talk about a project. JeanBaptiste identified that dialoguing about a project emphasizes the importance of a project over the importance of the people affected by it. Jean-Baptiste identified that focusing solely on the project was task-orientated, especially when speaking to the Indigenous stakeholders became an action of ticking the box. It made the project 
central, not the people. Jean-Baptiste learned from Elder Meade that this project-focused form of engagement is ineffective in understanding Indigenous Peoples' perspectives and needs. To see problems from different perspectives requires more than an hour meeting; it requires time, empathy, active listening, and listening more than speaking. Jean-Baptiste thought Elder Meade's guidance on working with Indigenous Peoples was a better way forward than what he had heard before, considering Canada's oppressive colonial history. He noticed that the engineering profession and how they communicate and foster relations with Indigenous Peoples could perpetuate harmful situations created in the past, or help improve them. The large responsibility it takes as an engineer when working on a project to positively impact others' lives was humbling to Jean-Baptiste.

To further consider how a relationship with Indigenous Peoples is different from a relationship with nonIndigenous engineering stakeholders, Jean-Baptiste reflected on his final year project in partnership with industry members. This partnership enabled senior engineering students to work with industry stakeholders to solve a real-world problem. To Jean-Baptiste, having discussions with industry partners does feel like checking the box; it is part of the routine process of consulting and gathering input, and it works well that way. If stakeholders are partners in a project from the same privileged ground, then a quick checking of the box is okay. However, when there is a historical imbalance of power of one group over the other, this engagement traditional and historical engineering process neglects Indigenous Peoples and their needs. In Jean-Baptiste's perspective, the building of relationships with Indigenous Peoples as an ongoing process as Elder Meade shared, was a better way forward for how settler/newcomer and Indigenous relationships can continue towards the direction of reconciliation.

Jean-Baptiste was deeply impacted by Elder Meade's words, but from the few conversations he had after class, wasn't sure that his peers and classmates were as impacted as he was. Maybe they did not value reconciliation as much? Maybe some students were more impacted? JeanBaptiste saw the value and importance of what Elder Meade had to say and how incorporating his guidance into engineering practice could positively influence many people's lives. Jean-Baptiste did not necessarily think that more formal instruction on co-existing with Indigenous Peoples in engineering education would correlate to increased student impact, because students often see their education and the courses they take as a means to an end to getting a degree; therefore, it becomes about getting a degree. As well, someone being told that they need to care about something is not as influential as a trusted guide coming alongside and letting one discover something for themselves. Jean-Baptiste also thinks that there needs to be more of a relational teaching method than just lectures to grasp the significance of learning about Indigenous
Peoples. He thinks empathy and its practical use, is essential for effective listening. Based on connecting with what people already value, Jean-Baptiste thought that the most significant link between engineering and Indigenous Peoples is in caring for the environment and managing natural resources well.

In the future, Jean-Baptiste hopes to see engineers able to identify differences in privilege and power in order to see other people's perspectives, and value reconciliation. On the micro-level, this could look like teaching engineering students who are interested in how to do projects with Indigenous Peoples and stakeholders, and learning how to foster relationships that do not perpetuate historical issues. He hopes for both Western and Indigenous worldviews to co-exist and have a strong intersecting point. For this to happen it will likely require a shift of engineering members from profit and projectcentric priorities to more emphasis on respectful relationships. Jean-Baptiste thinks that engineers have an ethical obligation to loosen their grip on their taskorientation, and be more caring of the people they are working with and for.

\section{DISCUSSION}

Jean-Baptiste recognized how approaching a relationship with Indigenous Peoples was different from what he commonly knew in the engineering community. He made the distinction of engagement between projectorientated (task-focused) and people-orientated (relationship-focused). The project-orientated approach used in engineering serves a very important purpose however it does have limits when used in the people-topeople relationships realm. To Jean-Baptiste, the socioculture of engineering tended to be project-orientated, so by default, that is engineers' way of engaging with other people. We see through Jean-Baptiste's story that this default form of engagement becomes problematic right from the beginning in working with Indigenous Peoples and Indigenous communities for several reasons. Firstly, because a greater effort in Canada has been/is being placed on the development of land to feed the needs of a Western society rather than the needs of Indigenous Peoples. Secondly, to enter into a relationship for the sake of a project, whether it be infrastructure, resources development, or agriculture, is to enter in with preconceived notions and objects that do not allow Indigenous perspectives to be heard. This engagement approach is not an example of 3rd space or ethical space because dialogue, thought, and actions stay central to one knowledge system - the dominant, and in this case, the Western one. If perspectives are heard, they are only recognized as a graft onto the prevailing system [8]. JeanBaptiste was able to see both an engineering perspective and an Indigenous perspective which provided information on the situational conflict or a discontinuity, as boundary 
crossing theory supports, between the engineering profession and Indigenous Peoples [13]. Jean-Baptiste experienced the first mechanism of boundary learning, identification, understanding how both communities relate and do not relate to one another [13]. Jean-Baptiste's background knowledge on privilege, and power, in situational contexts, "Canada's oppressive colonial history," and Elder Meade's guidance also helped him see the different perspectives.

Jean-Baptiste describes relationship-focused engagement as the ability to recognize one's positioning or reference system that influences their perspectives on how they see the world and their ability to pivot to understand someone else's reference system better. Relationshipfocused engagement is an approach to understand better other people's needs and how one's actions impact others. Sometimes our reference systems or worldviews can be fundamentally different, making it difficult and uncomfortable to pivot outside of our own to consider another person's reality and to have a relationship with them. Initially, pivoting one's perspective can challenge how one makes sense; of the world, their self-worth and, uncertainty. However, overcoming this challenge, in the spirit of genuine curiosity, and stepping into a 3rd space allows us to be vulnerable, meet others in the space, and share dialogue and stories with the potential to establish mutual communication and collaboration [13]. Here in this communicative connection, the second mechanism of boundary crossing, coordination, can be seen [13]. Through dialogue between people situated in different reference systems, meeting each other in 3rd space is where new knowledge is gained.

Jean-Baptiste's story supports the understanding that for engineers to engage with Indigenous Peoples meaningfully, their epistemic standpoint needs to transcend beyond the profession's status quo. If engineers knew how to engage with Indigenous Peoples and their ways of knowing and doing, would they incorporate this in professional practice? The engineering profession is demonstrated to lack cultural knowledge of what it means to co-exist in equitable and ethical space with Indigenous Peoples in engineering-related projects [20][21][22]. McCormack (2016) explains how oil and gas industry representatives, including engineers, engaged with Indigenous communities failed to exchange helpful information because of their lack of knowledge about traditional land use and Indigenous culture in northern Canada [20]. Johnson (2020) recognizes that mining engineering students need to understand intercultural competencies that are "shifting towards epistemic openness" to move towards decolonization [22]. In engineering education, students need to learn and practice relationship-focused skills, including cultural understanding and epistemic openness, to enter into a respectful relationship with Indigenous Peoples. JeanBaptiste's story supports this.
Jean-Baptiste's story demonstrates that active listening and being present by sitting down with the Elders and community members are examples of people-orientated skills that can help us enter into a 3rd space. Active listening requires stillness of the mind from continual processing and judgement of information [23]. This can be hard to do for an analytical engineering mind but is a skill that can be learned. People already in 3rd space can tell if someone else is there or not by their mental activity and their ability to actively listen. If one is not actively listening, their thoughts, comments and actions stay rooted in their original reference system. Active listening involves the listener's effort to reach a state of mental and or emotional empathy [23]. Being present with people physically relocates us to where they are. This, along with empathy, allows us to understand who people are, their values, and history, which likely expands or challenged our previous knowledge. Listening to and meeting with Indigenous Peoples and Communities to better understand their perspective takes time. The time given and the empathy used in active listening and when physically present with other people help us better understand their perspective and situation and is thus a mechanism for shifting one's reference systems and better understanding the realities of oneself and others.

Circling back to the project-orientated nature of engineering, to consider the function of checking the box. An approach to relationship-focused engagement in engineering education calls for engineering students and faculty to shift from task-based thinking to a less linearly structured or predefined mindset. The box has to be defined before it can be checked. This leads us to the following questions; who is defining the box? Who is ticking the box? What direction is progress growing? As engineers know, there are many interconnected tasks, elements, components, and moving parts that go into a project. Engineers become skilled at managing moving pieces and putting them all together to make something great. However, there is more to it than that, which engineers could begin to understand through a relational focus; relationship with self, other people, and the environment. Relationship with, is a continual process, continually adapting and navigating an underlying thread in which everything is created and connected. There is an abundance of valuable information and guidance to be found here. Further, the engineering community has recognized that the checking-the-box approach is not necessarily useful as there are always repercussions and are gradually moving away from that. This is especially been seen within technological stewardship [24].

To answer why Jean-Baptiste seems to take away more from Elder Meade's lecture than other students in his class, multiple factors need to be considered, such as students learning styles as global or sequential [25], as well as the zone of proximal development [26] or threshold concepts [27]. Jean-Baptiste's past experiences learning about 
empathy, power and privilege seem to have provided him with information that he could use to build from what Elder Meade was teaching. For example, before Elder Meade's teachings, Jean-Baptiste understood the concept of reconciliation and placed value on the process. These past experiences are not necessarily the same or even similar to those of his classmates. Thus, the diversity of students' past experiences and learning capacities are widely varied, and one approach to learning about Indigenous Knowledges and perspectives in a mandatory course may not have the impact on every student as it had on Jean-Baptiste. This suggests a more precise understanding of where students are at in their learning journeys, as many students are likely going to need guidance to enter the ethical space required for reconciliation in engineering education. Further analysis on the boundary crossing learning mechanism of identification, coordination, reflection and transformation is recommended in future research conducted for this study.

\section{CONCLUSIONS/IMPORTANCE FOR MEMBERSHIP}

This paper explored one student's story on their experiences in hearing an Elder-in-Residence speak about the impact of engineering on Indigenous Peoples and Indigenous communities in a core engineering course offered in the Price Faculty of Engineering at the University of Manitoba. This study uses the narrative three-dimensional space methodology and boundarycrossing theory to negotiate and represent the student's perspectives as an artifact of boundary crossing and provide insight into the exchange of cross-cultural knowledge. Findings reveal boundary crossing learning mechanisms of identification and coordination. For crosscultural knowledge to be exchanged, a relationship between engineering students and or educators and Indigenous knowledge holders has to be coordinated. Key factors allowing for a relationship to occur include engineers identifying Indigenous Peoples historical backgrounds, situational contexts, and values, which require active listening, genuine curiosity, empathy, and time. The research presented in this paper is part of a more extensive case study exploring the impact on students' learning when creating an ethical space for Indigenous Knowledges and perspectives in engineering education. These initiatives aim to create ethical and equitable space for Indigenous Peoples, so their knowledges and perspectives are visible and valued in the Price Faculty of Engineering community.

\section{Acknowledgements}

We are grateful to Elder Meade and for the teachings he offers to students and instructors in the Price Faculty of
Engineering, and for his guidance in this research work, and for his prayers to ensure that this work began in the spirit of reconciliation and continues in a good way. We are grateful for the student participant whose story is heard in this paper, and for the course instructor, and the students who are participating in this larger research study. We are thankful for their willingness to share their experiences, thoughts, ideas and feelings in order to advance the efforts to create ethical space for Indigenous Peoples in the Price Faculty of Engineering. We thank the CEEA-ACEG peerreviewers for their insightful and constructive comments. We thank the Department of Biosystems Engineering for creating the space and resources to conduct engineering education research. We are grateful to the University of Manitoba's Scholarship of Teaching and Learning Fund, and UM/SSHRC Explore grant for the funding to support a graduate student and make this work possible. This study is approved by the University of Manitoba's Research Ethics Board.

\section{References}

[1] First Nations and Indigenous Studies, Enfranchisement, The University of British Colombia. Available as of March 5, 2021 from https://indigenousfoundations.arts.ubc.ca/enfranchisem ent/

[2] Truth and Reconciliation Commission of Canada, Honouring the Truth, Reconciling for the Future: Summary of the Final Report of the Truth and Reconciliation Commission of Canada. The Truth and Reconciliation Commission of Canada, 2015, 535 pp. Available as of March 5, 2021 from http://nctr.ca/assets/reports/Final\%20Reports/Executive _Summary_English_Web.pdf

[3] Nelson Maldonado-Torres, "On the coloniality of being: contributions to the development of a concept," Cultural Studies, vol. 21, no. 2-3, pp. 240-270, March 2007.

[4] Jacqueline Ottmann, “Canada's Indigenous Peoples' access to post-secondary education: the spirit of the 'new buffalo," Indigenous Pathways, Transitions and Participation in Higher Education: From Policy to Practice, Springer Singapore, 2017, pp. 95-117.

[5] IISAAK OLAM Foundation, Indigenous Protected and Conserved Areas (IPCAs) and Ethical Space. Available as of March 5, 2021, from https://static1.squarespace.com/static/5a2f1db1c027d84 $2 \mathrm{f} 876 \mathrm{e} 280 / \mathrm{t} / 5 \mathrm{e} 28 \mathrm{ab} 03 \mathrm{c} 2509 \mathrm{c} 20 \mathrm{c} 65 \mathrm{c} 0 \mathrm{ca} 7 / 1579723524$ 248/IPCAs+and+Ethical+Space+-

+IISAAK+OLAM+Foundation+-+Dec+2019.pdf

[6] Michelle Pidgeon, "More than a checklist: meaningful Indigenous inclusion in higher education," Social Inclusion, vol. 4, no. 1, pp. 77-91, February 2016.

[7] Margaret Kovach, Jeannine Carriere, Harpell Montgomery, M. J. Barrett, and Carmen Gilles, Experiencing and Envisioning Indigenous Knowledges 
within Selected Post-Secondary Sites of Education and Social Work. Available as of March 7, 2021, from https://education.usask.ca/documents/profiles/kovach/I ndigenous-Presence-2014-Kovach-M-et-al.pdf

[8] Vanessa de Oliveira Andreotti, Sharon Stein, Cash Ahenakew, and Dallas Hunt, "Mapping interpretations of decolonization in the context of higher education," Decolonization: Indigeneity, Education \& Society, vol. 4, no. 1, pp. 21-40, 2015.

[9] Dustin William Louie, Yvonne Poitras-Pratt, Aubrey Jean Hanson, and Jacqueline Ottmann, "Applying indigenizing principles of decolonizing methodologies in university classrooms," Canadian Journal of Higher Education, vol. 47, no. 3, pp. 16-33, December 2017.

[10] Karen Ragoonaden and Lyle Mueller, "Culturally responsive pedagogy: indigenizing curriculum," Canadian Journal of Higher Education, vol. 47, no. 2, pp.22-46, 2017.

[11] J. Seniuk Cicek, A. L. Steele, D. Burgart, P. Rogalski, S. Gauthier, S. Mattucci, J. Bazylak, A. Mante, M. Robinson, R. Herrmann, and S. Staub-French "Indigenous initiatives in engineering education in Canada: collective contributions," in Proc. CEEA Canadian Engineering Education Conf., CEEA20 (Concordia and McGill Universities; 18-21 June 2020), 8 pp., 2020.

[12] Engineers Canada, Indigenous Peoples in Engineering, Available as of March 7, 2021, from https://engineerscanada.ca/diversity/indigenouspeoples-in-engineering

[13] Sanne Akkerman and, Arthur Bakker, "Boundary crossing and boundary objects," Review of Educational Research, vol. 81, no. 2. pp. 132-169, June 2011.

[14] Judith Gulikers and, Carla Oonk, "Towards a Rubric for Stimulating and Evaluating Sustainable Learning," Sustainability (Switzerland), vol. 11, no. 4, February 2019.

[15] Daniele T. P. Souza, Eugenia A. Kuhn, Arjen E. J. Wals, and Pedro R. Jacobi, "Learning in, with, and through the territory: Territory-based learning as a catalyst for urban sustainability," Sustainability (Switzerland), vol. 12, no. 7, April 2020.

[16] Peter P. Mollinga, "Towards the transdisciplinary engineer: incorporating ecology, equity and democracy concerns into water professionals' attitudes, skills and knowledge," Irrigation and Drainage, vol. 58, no. 2, pp. 195-204, April 2009.

[17] JoAnne Ollerenshaw and, John W. Creswell, "Narrative research: a comparison of two restorying data analysis approaches," Qualitative Inquiry, vol. 8, no. 3, pp. 329347, June 2002.

[18] John W. Creswell, and Cheryl N. Poth, Qualitative Inquiry \& Research Design: Choosing Among Five Approaches. Sage Publications, 2018 ( ( $^{\text {th }}$ ed.), $459 \mathrm{pp}$. \{ISBN 978-1-5063-3020-4\}
[19] Margaret Kovach, “A Round Dance?”, in Chpt. I Indigenous and Qualitative Inquiry: Characteristics, Conversations and Contexts. Toronto, ON; University of Toronto Press, 2009, 212 pp. \{ISBN 1442697644\}

[20] Patricia A. McCormack, "Environmental reviews and case studies: doing credible cultural assessment: applied social science," Environmental Practice, vol. 18, no. 3, pp. 148-165, 2016.

[21] Janelle Marie Baker, and Clinton N. Westman, "Extracting knowledge: social science, environmental impact assessment, and Indigenous consultation in the oil sands of Alberta, Canada," The Extractive Industries and Society, vol. 5, pp. 144-153, 2018.

[22] Anne Johnson, "A theoretical basis for addressing culture in undergraduate mining education," International Journal of Engineering, Social Justice, and Peace, vol. 7, no. 1, pp. 1-20, 2020.

[23] Sandra E. Spataro and, Janel Bloch, "“Can you repeat that?" Teaching active listening in management education," Journal of Management Education, vol. 42, no. 2, pp. 168-198, April 2018.

[24] Afua Adobea Mante, Marcia Friesen, and Kathryn Atamanchuk, "Advancing engineering education towards design for sustainable development at the University of Manitoba: initial assessment," in Proc. CEEA Canadian Engineering Education Conf., CEEA20 (Concordia and McGill Universities; 18-21 June 2020), 7 pp., 2020.

[25] Richard M. Felder and Linda k. Silverman, "Learning and teaching styles in engineering education," Engineering Education, vol. 78, no. 7, pp. 674-681, 1988.

[26] Lev Semenovich Vygotskiı̌, and Michael Cole. Mind in Society: the Development of Higher Psychological Processes. Cambridge, MA: Harvard University Press, 1978. \{ISBN 0674576284\}

[27] S. A. Male and D. Bennett, "Threshold concepts in undergraduate engineering: Exploring engineering roles and value of learning," Australasian Journal of Engineering Education, vol. 20, no. 1, pp. 59-69, January 2015. 